\title{
90. A Heavy Mentally Retarded Girl having Pericentric Inversion on No. 9 Chromosome (inv(9) (p13q21))
}

\author{
By Suzue Kanata,*) Tetsuji Kadotani,**) Yoko Watanabe,**) \\ Nami Matsuo,**) Hidetoshi Kodama,*) and Setsuji Kubo*) \\ (Communicated by Sajiro Makino, M. J. A., Sept. 12, 1985)
}

The pericentric inversion of chromosome no. 9 has been reported by several authors and these anomalies have been found with a frequency of about $1 \%$ in the human population (De La Chapelle et al. 1974; Fällström and Wahlström 1979). In a chromosome survey of a heavy mentally retarded girl, it was found to have a chromosome no. 9 having the pericentric inversion.

Case reports. The patient was an 11-year-old girl, $21.6 \mathrm{~kg}$ in weight, $130 \mathrm{~cm}$ in length. She was born to a 26-year-old mother and 30-year-old father as the first child. There was no history of abortion, stillbirth, congenital malformations, mental retardation, exposure to the atomic bomb, and consanguinity in this couple. Clinical examinations revealed that her parents and her younger brother were phenotypically normal.

The birth weight of the patient was $2750 \mathrm{~g}$ and the head circumference was $32 \mathrm{~cm}$ at 37 weeks of normal gestation. Her neonatal period was not particular. She stood up at 10 month and walked alone at 15 month. Her postnatal course seemed to be smooth and normal. At 3 years of age, she had a high temperature $\left(39^{\circ} \mathrm{C}\right)$ and convalsions continuously for one week. The diagnosis of encephalitis was made.

The remarkable clinical signs of this patient were developmental disorder; $21.6 \mathrm{~kg}(-3.0 \mathrm{SD})$ in weight, $130 \mathrm{~cm}(-1.9 \mathrm{SD})$ in length, micrognathia, slight kyphosis, club foot, incurved III. and IV. fingers with right, right hemiplegia, hypotonia, difficulty in walking and in coordination, seizure, mental retardation; idiot, speech disorder and behavior disorders; paraphagia, finger sucking. Her clinical features were complicated with cerebral palsy as the result of encephalitis (Fig. 1).

Cytological findings. The chromosome preparations were made on the leucocyte cultures from the patient and her mother. The G- and C-banding differential staining was applied for the chromosome identifications. The chromosome counts were made with 43 -well delineated metaphases. The karyotype was analysed in 20 cells by the conventional Giemsa staining, 9 cells by G-banding, and 14 cells by $\mathrm{C}$-banding differential staining.

The chromosome constitution of the patient based on the conventional Giemsa specimen showed 46 chromosomes which included a chromosome no. 9 having an unusually elongated short arm and shortened long arm. The G- and C-banding analyses revealed that one of the chromosome no. 9 showed the pericentric inversion at $\mathrm{p} 13 \rightarrow \mathrm{q} 21$. Then the chromosome formula of this patient was given as 46,XX,inv (9) (p13q21) (Fig. 2). Her mother was chromosomally normal with

*) Psychiatric Department, Kamo National Sanatorium, Kurose-cho, Kamo-gun, Hiroshima, Japan.

**) The Kadotani Medical Research Foundation. 1248, Saijohigashi, Saijo, Higashihiroshima, 724, Japan. 
[Vol. 61(B),

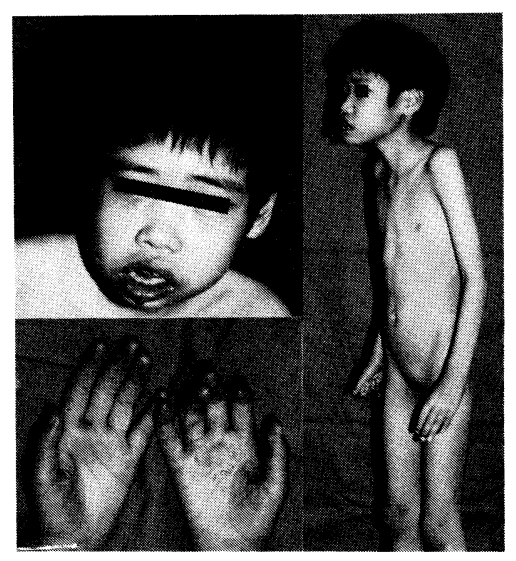

Fig. 1. External pictures of the patient.

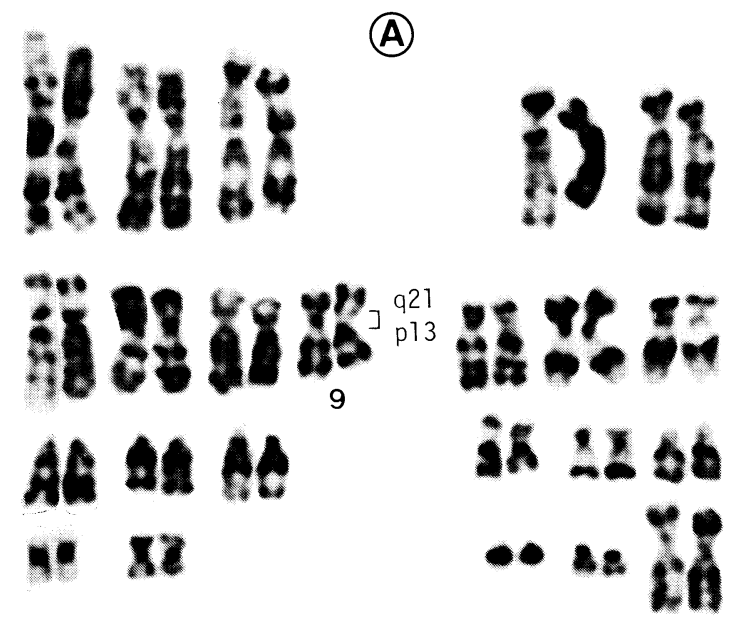

(B)

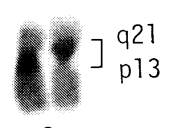

9

Fig. 2. G-banding karyotype (A) and partial C-banding karyotype (B) of the patient, showing 46,XX,inv(9) (p13q21).

no evidence for the aberration. The chromosomal examination of her father and younger brother was not cooperated.

Remarks and conclusion. It has been well known that the chromosome no. 9 showed a high susceptibility for the structural rearrangements. And it is very interesting that the most frequent rearrangement of chromosome no. 9 was a pericentric inversion and most of the inverted segments included the total constitutive heterochromatin.

The application of G- and C-banding techniques made it possible to reveal 
the exact point of breakage. But the features of the case with pericentric inv (9) were variable. Howard-Peebles and Stoddard (1979) classified the inv(9) into four major groups: (1) phenotypically normal; (2) phenotypically normal but with reproduction failure or at least reduced fertility; (3) phenotypically abnormal due to another chromosomal abnormality; and (4) phenotypically abnormal with multiple congenital malformations.

In reference to the past reports on inversion no. 9 chromosome by this criteria, group (2) was reported on 20 cases: Four cases with the inverted segment $\mathrm{p} 1 \rightarrow \mathrm{q} 13$ were reported by De La Chapelle et al. (1974) and by Pescia et al. (1977), 10 cases were reported by Boué et al. (1975), two cases with $\mathrm{p} 11 \rightarrow \mathrm{q} 13$ were reported by Shiraishi and Makino (1977), one case with $\mathrm{p} 12 \rightarrow \mathrm{q} 12$ was reported by Kahn et al. (1978), one case with two different pericentric inversion of no. 9 chromosome both $\mathrm{p} 11 \rightarrow \mathrm{q} 1209$ and pter $\rightarrow \mathrm{q} 1209$ was reported by Croquette (1979), one case with $\mathrm{p} 12 \rightarrow \mathrm{q} 13$ was reported by Howard-Peebles and Stoddard (1979), and one case with $\mathrm{p} 23 \rightarrow \mathrm{q} 31$ was reported by Debevec and Canki (1982). Group (3) was reported on 8 cases: Two cases with mosaic trisomy of no. 9 chromosome were reported by Schinzel et al. (1974) and by Frydman et al. (1978), one case with $\mathrm{p} 1 \rightarrow \mathrm{q} 13$ with Turner syndrome was reported by De La Chapelle et al. (1974), one case with $t(1 ; 7)$ (p13q12) was reported by Boué et al. (1975), one case with p11 $\rightarrow$ q13 and $t(12 ; ?)(p 13 ; ?)$ was reported by Summitt et al. (1977), one case with $\mathrm{p} 11 \rightarrow \mathrm{q} 13$ with Down syndrome was reported by Hernandez et al. (1979), and 2 cases with $\mathrm{p} 13 \rightarrow \mathrm{q} 13$ and $\mathrm{p} 13 \rightarrow \mathrm{q} 21$ with Down syndrome were reported by Howard-Peebles and Stoddard (1979). Group (4) was reported on 15 cases: Three cases with inverted segment $\mathrm{p} 1 \rightarrow \mathrm{q} 13$ of no. 9 chromosome were reported by De La Chapelle et al. (1974) and by Pescia et al. (1977), 4 cases were reported by Karmon et al. (1978), one case with $\mathrm{p} 12 \rightarrow \mathrm{q} 21$ was reported by Howard-Peebles and Stoddard (1979), one case with p12 $\rightarrow$ q13 was reported by Fällström and Wahlström (1979), two cases with $\mathrm{p} 13 \rightarrow \mathrm{q} 13$ were reported by Kirillova et al. (1979), three cases with $\mathrm{p} 11 \rightarrow \mathrm{q} 13$ were reported by Kadotani et al. $(1981,1985)$ and by Kanata et al. (1985), and one case with $\mathrm{p} 23 \rightarrow \mathrm{q} 31$ was reported by Kadotani et al. (1984).

To date, the relationship between the inverted segment and the clinical features was not yet revealed. We hope further investigation of the pericentric inversion of the chromosome no. 9 in order to assess the certain relationship between chromosome aberrations and clinical features.

Acknowledgements. We are cordially obliged to Emeritus Professor Sajiro Makino, M. J. A., the senior director of the Kadotani Medical Research Foundation, for improvement of this manuscript. Financial aid from the Japan Academy is gratefully acknowledged here.

\section{References}

Boué, J. et al. (1975) : Humangenetik, 30, 217-224.

Croquette, M. F. et al. (1979) : Ann. Génét., 22, 53-56.

De La Chapelle, A. et al. (1974) : Am. J. Hum. Genet., 26, 764-766.

Debevec, M., and Canki, N. (1982) : ZDRAV VESTN, 51, 443-446.

Fällström, S., and Wahlström, J. (1979) : Clin. Genet., 15, 480-486.

Frydman, M. et al. (1981) : J. Med. Genet., 18, 390-392.

Hernandez, A. et al. (1979) : Ann. génét., 22, 40-42.

Howard-Peebles, P. N., and Stoddard, G. R. (1979) : Hum Hered., 29, 111-117.

Kadotani, T. et al. (1981) : Proc. Japan Acad., 57B, 378-380. 
Kadotani, T. et al. (1984) : ibid., 60B, 92-94.

Kadotani, T. et al. (1985) : ibid., 61B, 134-136.

Kanata, S. et al. (1985) : ibid., 61B, 242-244.

Karman, G. et al. (1978) : Metab. Ophthalm., 2, 213-214.

Khan, G. et al. (1978) : J. Clin. End. Metab., 47, 280-283.

Kirillova, E. A. et al. (1979) : Tistol. Genet., 13, 300-304.

Pescia, G. et al. (1977) : J. Génét. Hum., 25, 121-134.

Schinzel, A. et al. (1974) : Humangenetik, 25, 171-177.

Shiraishi, Y., and Makino, S. (1977): Proc. Japan Acad., 53, 79-82.

Sumitt, R. L. et al. (1977) : Europ. J. Pediat., 125, 169-174. 